\title{
Application of Bronze Decorative Patterns in Fashion Design in Shang and Zhou Dynasties
}

\author{
${ }^{1}$ Dalian Polytechnic University, Ganjingzi, Dalian, Liaoning, China \\ ${ }^{2}$ Dalian Polytechnic University, Ganjingzi, Dalian, Liaoning, China \\ ${ }^{3}$ Dalian Polytechnic University, Ganjingzi, Dalian, Liaoning, China \\ a2270686379@qq.com \\ b657762970@qq.com \\ c747086535@qq.com
}

Zhang Jiaojiao ${ }^{1, \text { a }}{\text { Zhao } \mathrm{Fu}^{2, b^{*}} \text { Wang Junying }}^{3, \mathrm{c}}$

\begin{abstract}
Starting with the historical background and formation style of bronze art in the Shang and Zhou dynasties, this paper analyzes and summarizes the characteristics and significance of bronze decorative patterns, and discusses the application of bronze decorative patterns in clothing from the aesthetic characteristics of bronze patterns.
\end{abstract}

Keywords: Bronze pattern, Decorative aesthetic, Clothing design

\section{商周时期青铜装饰纹样在服装设计中的应用}

\author{
'大连工业大学, 甘井子, 大连, 辽宁, 中国 \\ 2 大连工业大学, 甘井子, 大连, 辽宁, 中国 \\ ${ }^{3}$ 大连工业大学, 甘井子, 大连, 辽宁, 中国 \\ a2270686379@qq.com \\ b657762970@qq.com \\ c747086535@qq.com
}

张娇娇 $^{1, a}$ 赵甫 $^{2,} \mathrm{~b}^{*}$ 王珺英 ${ }^{3,}$

\section{摘要}

文章从商周青铜艺术的历史背景与形成风格入手, 分析并归纳了青铜器装饰纹样的特点与意义, 从青铜器纹样 的美学特征入手探讨青铜装饰纹样在服装中的应用。

关键词: 青铜纹样, 装饰美学, 服装设计

\section{1. 前言}

青铜器作为国之瑰宝, 具有很高的历史价值、文 化价值和艺术价值。我国的青铜文化历经了几千年的 历史沉淀, 成为了中华文化的精髓, 商周时期作为青 铜器发展的鼎盛时期, 在其造型、纹样、工艺材料等 方面都趋向于成熟, 具有其独特的艺术风格。青铜器 在造型及纹样的研究被广泛运用于服装设计领域, 是 对传统文化的弘扬及对现代设计的融合探索。

\section{2. 青铜器的概念与艺术风格}

青铜器是通过铜、锡等合金烧制而成的器物, 本 身是金色, 经过氧化后形成青绿色铜锈。青铜器作为 国之重器, 历经了兴衰, 在人类社会文明的发展进程 中起着举足轻重的作用。据文献记载, 早在始祖黄帝 之时便会制造青铜器，据《史记》中提到：“黄帝采 首山铜, 铸鼎于荆山下。 ${ }^{[1]}$ 后在二里头遗址中发现青 铜器有着早期原始艺术的影子, 造型简单, 纹样粗犷 单纯。 
商代晚期作为青铜器发展的鼎盛时期, 与此前相 比, 青铜器在数量上、制作工艺上、造型、纹样等方 面都趋于成熟和稳定。商朝手工业的发达带动了青铜 器的发展, 青铜器成为了统治阶级地位的象征也是通 天地神灵的纽带。在礼乐制度下, 这个时期的青铜器 无论在造型还是纹样上都蕴含着宗教、政治意义。商 代晚期青铜器造型庄严凝重、神秘而充满狰狞感, 纹 样较为复杂繁琐, 整体较为恐怖, 成为统治阶级的权 力象征。

西周初期, 由于在宗法礼制的桎梏下，青铜艺术 依旧承袭商晚期的特点风格较为凶猛神秘, 到了中后 期, 随着政治、经济、宗法制度的完善, 社会的发展 淡化了青铜器的神秘色彩。随着人意识的觉醒, 种类 增多, 青铜器在造型装饰上更突出理性与现实。青铜 器摆脱了繁杂的装饰效果, 更多采用现实中存在的形 象进行创造，简单朴素成为了社会风尚。

到了东周时期, 青铜器较为精美华丽, 风格更为 立体、写实。装饰也更有趣味意义, 纹样镂空浮雕装 饰达到了创作的顶峰时期。

\section{3. 青铜器的装饰纹样}

青铜文化是商周时期最有艺术价值的体现, 其中 青铜器纹样发挥着举足轻重的作用, 青铜器纹样作用 不仅仅只有装饰, 它象征着时代精神, 体现着社会的 政治、宗教与文化。商周时期青铜器在礼乐制度和宗 法制度的影响下, 青铜器风格由简单粗犷逐渐发展成 精致繁杂, 纹样也复杂多样, 纹饰主要以几何纹和动 物纹为主, 商周时期最为广泛运用的几何纹有: 窃曲 纹、云雷纹、重环纹、垂鳞纹、环带纹、乳钉纹等如 表 1, 动物纹样有: 兽面纹、龙纹、凤鸟纹、以及其 他象生纹样如表 $2^{[2]}$ 。

兽面纹又称饕䬸纹, 是商周时期青铜器上的典型 纹样, 象征着 “上帝” 具有震撼威慑的功能, 主要装 饰在青铜器腹部。纹饰集中了多种动物形象进行抽象 夸张, 纹饰正面采用兽面进行装饰, 兽面纹的角借鉴 羊或鹿的角、牛的眼睛与鼻子, 老虎的嘴进行组合形 成一种神秘、狰狞庄严之感。

龙纹是商周青铜器较为流行的纹样之一, 龙象征 着中华民族, 有庇护守护的寓意。商周青铜器最为典 型的是頌龙纹又称頌纹, 通常为一足一角, 卷尾张口

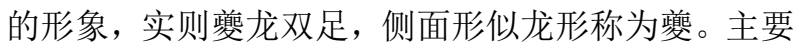
装饰在青铜器的口部与颈部位置以及组合形成兽面 纹。之后随着工艺水平的提高, 龙纹的种类复杂多样, 例如爬行龙纹、卷龙纹、蟠龙纹、交体龙纹等。

凤鸟纹包括了凤和鸟的形象, 凤被称为 “百鸟之 王”, 神灵的象征。凤的形态与鸟相似, 形态较为写 实, 西周时期宗法制度下, 对血缘与伦理较为重视, 提倡 “尊祖敬德”、“敬天保民” 的思想。凤鸟的形态 更多象征着和平、安宁、吉祥, 青铜艺术风格摆脱了 商朝的威严恐怖形象。青铜器的纹样还包括写实性的
动物纹样, 都是将动物形象进行整理、概括、提取进 行创作, 包括象纹、虎纹、蝉纹、鱼纹等 ${ }^{[3]}$ 。

表 1 青铜器几何纹样

\begin{tabular}{|c|c|c|c|}
\hline $\begin{array}{c}\text { 纹 } \\
\text { 样 } \\
\text { 名 }\end{array}$ & 纹样特点 & 纹样图例 & 装饰 \\
部位 \\
\hline 妳
\end{tabular}

表 2 青铜器动物纹样

\begin{tabular}{|c|c|c|c|}
\hline $\begin{array}{l}\text { 纹样 } \\
\text { 名称 }\end{array}$ & 纹样特点 & 纹样图例 & $\begin{array}{c}\text { 象征意 } \\
\text { 义 }\end{array}$ \\
\hline $\begin{array}{l}\text { 鲕 } \\
\text { 纹 }\end{array}$ & $\begin{array}{l}\text { 主体正面为兽 } \\
\text { 头形象, 鼻梁 } \\
\text { 位于央, 左右 } \\
\text { 两边对称, 两 } \\
\text { 眼较为突出, } \\
\text { 口大, 有角和 } \\
\text { 耳, 身体两侧 } \\
\text { 对称展开, 有 } \\
\text { 的两侧连着爪 } \\
\text { 和尾。 }\end{array}$ & 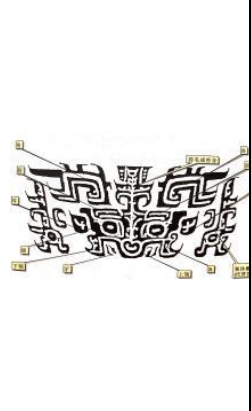 & $\begin{array}{l}\text { 对自然 } \\
\text { 的崇拜 } \\
\text { 与敬 } \\
\text { 畏, 用 } \\
\text { 来表达 } \\
\text { 政治地 } \\
\text { 位权力 } \\
\text { 的象 } \\
\text { 征。 }\end{array}$ \\
\hline
\end{tabular}




\begin{tabular}{|c|c|c|c|c|}
\hline \multicolumn{2}{|c|}{$\begin{array}{l}\text { 剩 } \\
\text { 纹 } \\
\text { 纹 }\end{array}$} & $\begin{array}{l}\text { 悲龙纹身体强 } \\
\text { 壮, 眼睛、嘴 } \\
\text { 巴较大, 身体 } \\
\text { 细而长, 以直 } \\
\text { 线为主, 全身 } \\
\text { 像龙而只有一 } \\
\text { 足。 }\end{array}$ & & $\begin{array}{l}\text { 龙作为 } \\
\text { 人类的 } \\
\text { 始祖 } \\
\text { 神, 有 } \\
\text { 庇护之 } \\
\text { 意。 }\end{array}$ \\
\hline $\begin{array}{l}\text { 凤 } \\
\text { 鸟 } \\
\text { 纹 }\end{array}$ & ti & $\begin{array}{l}\text { 凤鸟纹以侧面 } \\
\text { 主, 头为圆形, } \\
\text { 中间有眼, 嘴 } \\
\text { 似尖钩, 身体 } \\
\text { 较短, 大多为 } \\
\text { 直立, 尾巴上 } \\
\text { 卷。 }\end{array}$ & 俞 & $\begin{array}{l}\text { 凤为百 } \\
\text { 鸟首是 } \\
\text { 吉祥 } \\
\text { 鸟。 }\end{array}$ \\
\hline \multirow{4}{*}{$\begin{array}{l}\text { 其 } \\
\text { 他 } \\
\text { 象 } \\
\text { 生 } \\
\text { 纹 } \\
\text { 样 }\end{array}$} & $\begin{array}{l}\text { 象 } \\
\text { 纹 }\end{array}$ & $\begin{array}{l}\text { 象纹体型粗 } \\
\text { 大, 鼻子下垂。 } \\
\text { 身上饰云雷 } \\
\text { 纹。身内以螺 } \\
\text { 旋纹为主。 }\end{array}$ & 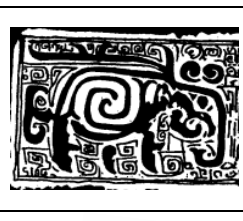 & $\begin{array}{l}\text { 沉稳大 } \\
\text { 气聪明 }\end{array}$ \\
\hline & $\begin{array}{l}\text { 虎 } \\
\text { 纹 }\end{array}$ & $\begin{array}{l}\text { 虎纹身形较 } \\
\text { 大, 夸张虎口, } \\
\text { 尾巴作卷尾 } \\
\text { 状, 较为凶恶。 }\end{array}$ & & $\begin{array}{l}\text { 百兽之 } \\
\text { 君威猛 } \\
\text { 强健具 } \\
\text { 有趋吉 } \\
\text { 避凶的 } \\
\text { 作用。 }\end{array}$ \\
\hline & $\begin{array}{l}\text { 蝉 } \\
\text { 纹 }\end{array}$ & $\begin{array}{l}\text { 蝉纹无足, 大 } \\
\text { 多呈三角状, } \\
\text { 腹部用节状条 } \\
\text { 纹填充, 四周 } \\
\text { 装饰云雷纹。 }\end{array}$ & 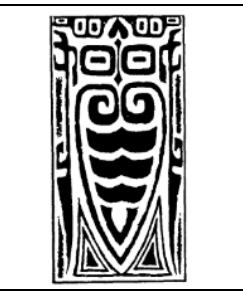 & $\begin{array}{l}\text { 代表重 } \\
\text { 生和永 } \\
\text { 生。用 } \\
\text { 来祭 } \\
\text { 祀, 获 } \\
\text { 得神灵 } \\
\text { 庇佑。 }\end{array}$ \\
\hline & $\begin{array}{l}\text { 蛇 } \\
\text { 纹 }\end{array}$ & $\begin{array}{l}\text { 蛇纹, 呈弯曲 } \\
\text { 状, 圆眼, 用 } \\
\text { 云雷纹或鳞纹 } \\
\text { 装饰。 }\end{array}$ & 3. & $\begin{array}{l}\text { 重生与 } \\
\text { 死亡, } \\
\text { 沟通天 } \\
\text { 地。 }\end{array}$ \\
\hline
\end{tabular}

\section{4. 青铜器纹样的装饰法则}

\section{1 对称与均衡}

早期的青铜器继承了新石器时代的原始气息, 青 铜器经过了千年的历史沉淀, 装饰纹样随着社会的发 展变得形态各异, 风格多样, 但是变化中依然遵遵循 着时代的规律。早在原始社会器物上图案就有对称形 态。在商周时期, 青铜器被作为礼器, 不仅在纹样上 有轴对称还有几何纹样中的中心对称, 器物也成双成 对, 甚至在祭祀中的摆放上也具有对称性 ${ }^{[4]}$ 。最为典 型的便是䬭䬸纹 (如图 1), 分布在众多青铜器中, 以鼻子为中线, 左右两边图案呈对称性, 在对称的同
时, 通过对其他动物的组合变形, 形成微妙的变化完 成从具象到抽象的变化, 让原本严肃的纹样充满了神 秘感和灵动感。

\section{2 节奏与韵律}

青铜器在视觉上通过交替变化体现出来的节奏 感和韵律感, 通常在器物的整体或几何纹样中, 青铜 器纹饰有主次, 通过主体纹饰和助纹饰搭配形成差异, 青铜器上有些适合纹样通过有规律的进行图案的排 序形成一种节奏美感 (如图 2)。纹饰的起伏、大小, 疏密会带来层次感, 形成秩序美, 带来不同的视觉感 受, 也决定了纹样的风格和特征。

\section{3 对比和调和}

青铜器纹样中通常会用对比和调和的手法实现 均衡, 通过对比手法形成个体差异性, 从而突出重点。 青铜器中鼔䬸纹经常与咅龙纹、鸟纹等 (如图 1), 通过对比祄托䬭䬸纹的凶猛威严, 而鸟纹作为一种吉 祥和平的象征, 活泼、安详形成一种缓和的作用使饕 䬸纹样不那么狰狞严肃。青铜器中动物纹样与几何纹 样的搭配（如图 3)、几何纹中方圆的搭配, 都形成 了对比调和的作用, 在差异中形成完整统一, 也让青 铜器纹饰充满了装饰趣味。

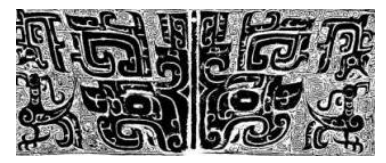

图 1 䭌䬸纹

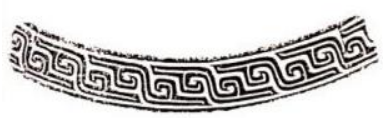

图 2 窃曲纹

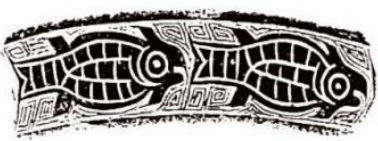

图 3 鱼纹

\section{5. 青铜器纹样在服装设计中的应用}

\section{1 在服装图案的应用}

青铜器装饰纹样内容丰富题材多样, 是对当时社 会的反映, 青铜器兽面纹形象带给人一种威严、恐惧, 也让人从心底里产生敬畏。但在新的社会背景下, 青 铜纹样的精美运用在服装图案上带来不一样的视觉 体验。青铜纹样在服装设计中可以打破直接运用, 在 原有的象征意义的基础上利用解构打散重组拼接, 运 用形式美法则, 进行对称均衡、体现节奏和韵律, 达 到整体的统一。在国潮的发展和带动下, 利用手绘让 纹样形象 Q 版化, 运用在服装中让现代设计更加有活 力 (如图 4, 图 5), 也使本土的、民族的文化更有魅 力。 


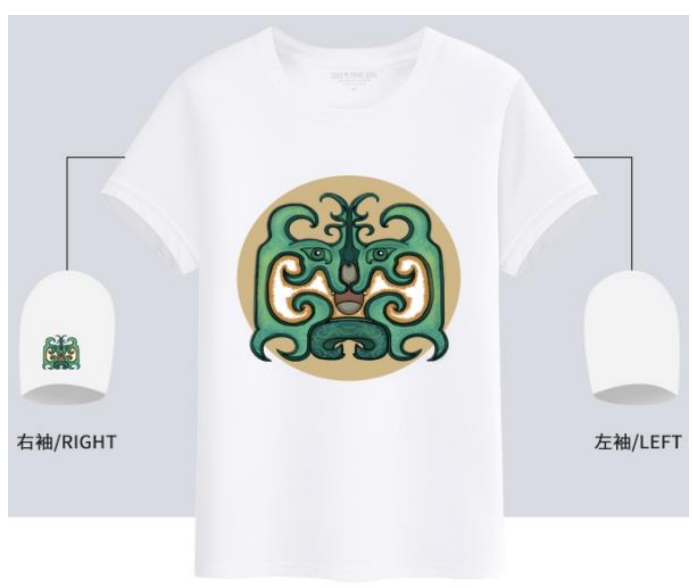

图 4 龙纹运用在 T 恤上

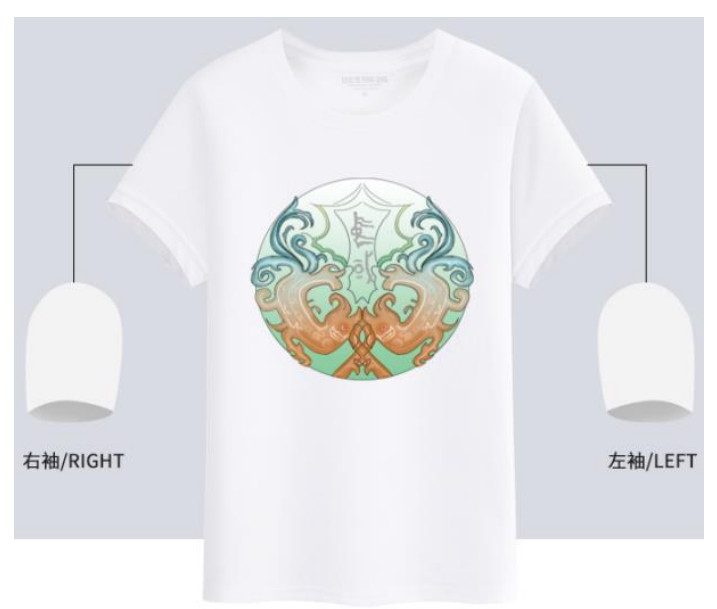

图 5 凤鸟纹运用在 $\mathrm{T}$ 恤上

\section{2 在服装色彩中的应用}

色彩作为视觉突出的设计元素在服装中不可或 缺, 青铜色彩原本是金色, 由于青铜在空气中氧化表 面会形成色迹斑斑铜绿色, 将服装中运用青铜色, 让 服装更具有历史色彩。通过对青铜色彩的提炼, 运用 扎染、蜡染等技术结合图案实现服装上的青铜色彩, 既多元化又个性化。随着消费群体的年轻化, 数码印 花的环保及个性化成为了大的趋势, 通过电脑的控制 让青铜元素运用在服装中, 既弘扬了传统文化, 又散 发着个性和时尚的气息。

\section{3 在服装工艺中的应用}

通过工艺的手段提升服装表现力, 工艺手段可以 将服装丰富, 更为细节的体现服装的内涵。青铜元素 与刺绣的结合, 是一种简约与精美的碰墥, 传统与现 代的碰撞, 能为服装增添华丽的气息。还可以运用编 织, 浮雕刻花的工艺在服装局部增加立体感, 通过对 比手法, 突出服装细节, 青铜的肌理通过工艺手法起 到装饰效果, 为服装增添美感, 创造出多样化可能性。

\section{6. 结语}

青铜器作为国之重器, 具有重要的历史价值、文 化价值和艺术价值, 青铜时代是中华文明的形成阶段, 为中华文明的传统文化的奠定了结实的基础。青铜纹 样历经几千年的沉淀, 由简单粗犷到繁冗复杂, 随着 岁月和智慧的结晶形成了独具特色的艺术风格, 传统 文化的发展, 青铜纹样与现代服装设计的结合必然成 为一种潮流。近年来, VR, 三维建模或 $3 \mathrm{D}$ 自动成像 技术带动博物馆、考古事业的不断发展, 文物保护被 提上日程, 让文物活起来也成为了热门话题, 作为我 国古代文明的重要遗产, 青铜器因其珍贵的铭文、华 美的纹饰及独特的造型等得到世人的关注。中国元素 逐渐被大家流传借鉴, 弘扬和传承民族文化促使国潮 兴起, 将青铜文化运用在服装设计中不仅增强民族自 信, 也提升了服装设计的审美感受, 让中华文化走进 生活, 带向世界, 为青铜文化和服装设计创造出更多 的可能性。

\section{项目基金}

本文为 2021 年辽宁省社会科学规划基金重点项 目《辽宁省民间手工艺的保护与振兴研究》 (L21AMZ002) 的阶段性成果之一。

\section{REFERENCES}

[1] Li Boqian ,L.(2018)Bronze ware and Chinese bronze age. University of science and technology of China Press,Hefei.

[2] Zhou Siyang,Z.Wan Shan,W.(1993)A collection of Chinese bronze designs. Shanghai Bookstore press, Shanghai.

[3]Liu Hejun,L,. Sun Xing,S. Zhu Hongxia,Z.(2018)Regeneration of bronze patterns in modern art design.Journal of Huizhou University.2018, 38 (01): 99-103. 38 (01): 99-103.

[ 4 ]Chen Yanhui,C(2009).Bronze Age: the cultural background of bronze inscriptions in Shang and Zhou Dynasties.Academic exchange, 2009 (03): 164-167. 